\title{
Effectiveness of "Instrumental Music" on Feeling of Wellbeing among Patient Undergoing Chemotherapy in Tertiary Care Hospital, Karad
}

\author{
Ajit Anandrao Pawar ${ }^{1}$, Prabhuswami Hiremath ${ }^{2}$, Nutan Potdar $^{3}$, Parshuram Prakashrao Naikawadi $^{4}$ \\ ${ }^{1}$ M.Sc. Nursing \\ ${ }^{2}$ Lecturer, KINS, Karad \\ ${ }^{3}$ Lecturer, KINS, Karad. \\ ${ }^{4}$ M.Sc. Nursing
}

\begin{abstract}
This research aimed to determine the effect of instrumental music on feeling of well being of cancer patients undergoing chemotherapy. Cancer disrupts physical and emotional well-being and results in range of negative emotions. Music therapy is an effective form of supportive cancer care for patients during the treatment process to improve physical and emotional well-being. An evaluative research approach, and quasi-experiment design was used for the study. The sample consists 30 patients each in control and experimental group. The data was collected by structured questionnaire. Experiment group received music therapy along with chemotherapy for once at the time for 1 hour. RESULT shows for pretest in control group mean 45.66 and experiment group mean 46.63, Mean difference was $0.97, t$ value is 0.27 and $p$ value is 0.79 this indicate that it is not significant. The posttest reveals in control group mean 42.93 and experiment group mean 53.50, Mean difference is 10.57, $t$ value is 3.93 and $p$ value is 0.0002 this indicate that it is highly significant so insrumental music is supportive treatment to promote wellness, improve physical and emotional well-being and the quality of life.
\end{abstract}

Keywords: Instumental Music, chemotherapy patients, Feeling of well being

\section{Introduction}

Chemotherapy drugs help to destroy cancer cells, prevent cancer from spreading, slow the cancer's cell growth and relieve the symptoms. Chemotherapy may be prescribed on a daily, weekly or monthly basis. Chemotherapy drugs can affect some of the normal cells also and it leads to unpleasant side-effects such as nausea, vomiting, loss of appetite, hair loss, stress, anxiety, pain, discomfort and causes changes in the vital signs.

There are so many complementary therapies to treat the side-effects of the chemotherapy and one of them is music therapy.

"I think music in itself is healing. It is something we are all touched by. No matter what culture we're from, everyone loves music."

BILLY JOEL (2005) Music therapy is evidence-based complementary therapy that enhances quality of life in cancer patients and their caregivers. Music promotes relaxation and has been found to reduce pain.

Music is the most powerful catalyst, bringing people together, breaking through isolation and generating positive social energy. Music therapy is the prescribed use of music by a well qualified person to effect positive changes in the holistic system that is physical, psychological, cognitive and social functioning of the individuals with health, emotional or educational problems. It is used successfully in children, adolescents, adults and the elderly with mental health needs.
Patients coming to the hospitals for undergoing any type of invasive procedures often may experience anxiety. Even minor invasive procedures can produce anxiety in patients and affect their post procedural recoveries, in particular, increase their risk of physiological complications. Anticipating the procedure can lead to fear and anxiety for people who associate procedures with pain, possible disfigurement and dependency. Providing therapeutic music may help to relieve anxiety in these patients.

According to Ginghams. J (2001) music therapy helps to, Decrease nausea during chemotherapy, Improve participation in medical treatment that shortens hospital stay, Relieve anxiety, Improve mood, Reduce the pain perception, Ease depression, Enhance concentration and creativity.

Carol L Kornmehi (2003) emphasizes that music therapy has a well defined role in oncology, as well as in other areas of medicine. When people are stressed, their bodies release epinephrine, nor-epinephrine and other compounds that cause the muscle to tone. Scientific evidence shows that music reduces blood pressure, heart rate, depression, insomnia and anxiety ${ }^{1}$.

Researchers have found that music can enhance the efficacy of anti-nausea drugs for patients who receive high-dose chemotherapy. A number of clinical trials have demonstrated that music also augments the effects of pain medication and stimulates the circulation of endorphins, the chemicals produced by the body to control pain and create a sense of well-being. 


\section{International Journal of Science and Research (IJSR) \\ ISSN (Online): 2319-7064}

Index Copernicus Value (2015): 78.96 | Impact Factor (2015): 6.391

\section{Review of Literature}

A study conducted by Ferrier A.J. (2007) to examine the effect of music therapy (MT), immediate and overtime on the psychological functioning, quality of life and physiological stress arousal of the patient. Randomized controlled design was used and totally 70 women participated in this study all of them received music therapy. Pain was assessed using the visual analog scale; heart rate and blood pressure were also assessed for the music therapy group immediately before and after the individual session. Significant immediate effect of music therapy were observed; there was significant difference in the (relaxation, comfort, happiness) $\mathrm{p}=<.00001$, and heart rate $\mathrm{p}=<.00003^{2}$.

Vasanthakalyani C. (2007) conducted a study to evaluate the effectiveness of music therapy on pain and anxiety among cancer patients at Apollo hospital, Chennai. Using purposive sampling technique with sample size of 30 cancer patients was taken. Results found that the pain score of the cancer patients was high before-M=8.31, $\mathrm{SD}=1.39$, in comparison with the scores after the music therapy $\mathrm{M}=2.49$, $\mathrm{SD}=0.90$. The difference was significant at $95 \%$ level of confidence. The level of anxiety in cancer patients was high $\mathrm{M}=51.6, \mathrm{SD}=7.40$. And after music therapy it was found to be less- $\mathrm{M}=55(5 \mathrm{SD}=5.28)$. The difference was statistically proven to be significant $(\mathrm{p}<0.001)$. The tools used by the investigator were, demographic variable proforma, 0-10 pain intensity scale, Spielberger's state anxiety sub scale and assessment tool on physiological response to music therapy.

Sendelbach, Sue E. et al. (2006) conducted a study on effects of music therapy on physiological and psychological outcomes for patients undergoing cardiac surgery. The sample composed of 86 patients $(69.8 \%$ males $)$ and were randomized to 1 of 2 groups, 50 patients (experimental group) received 20 minutes music, whereas 36 patients had 20 minutes of rest in bed(control group).A significant reduction in anxiety $(\mathrm{p}<0.001)$ and pain $(\mathrm{p}=0.009)$ was demonstrated in the group that received music compared with the control group, but no difference was observed in systolic blood pressure $(\mathrm{p}=0.17)$, diastolic blood pressure $(\mathrm{p}=0.11)$ or heart rate $(\mathrm{p}=0.76)$. The study concluded that patients are benefited from music therapy ${ }^{4}$.

Martha D. Buffum (2006) conducted study on music intervention to reduce anxiety before vascular angiography procedures, a randomized controlled trial of 170 patients was undertaken to determine whether 15 minutes of selfselected music reduced pre-procedure anxiety. The State Trait Anxiety Inventory was used to measure patients' anxiety. One-hundred sixty-six men and 4 women comprised the sample with an average age of 66.8 years (SD 9.95, range 37 to 85 years). Patients who listened to music $(n=89)$ reduced their anxiety score from 38.57 (SD 10.46) to 35.2 (SD 9.7), while those who did not listen to music $(n=81)$ reduced their anxiety score from 36.23 (SD 10.54) to 35.1 (SD 10.59); the difference between the groups was statistically significant $(\mathrm{t}=1.95$, df $161, \mathrm{p}=0.05)$. Pulse achieved a statistically significant reduction in the music group ( $\mathrm{t}=2.45$, df $167, \mathrm{p}=0.02$ ). Music is a non-invasive nursing intervention that patients enjoy and reduces their anxiety and their pulse rate. The study recommended that further research should address using music to reduce anxiety in other interventional vascular angiography settings with equal numbers of men and women and comparing selfselected versus investigator-selected music. ${ }^{5}$

A study conducted by Springer Berlin (2006) to evaluate the effect of music on oncology out patients. At visit 1 , Patients rested for 20mins; at visit 2, for 20mins they listened to music designed to increase vitality and improve heart rate variability (HRV). At both visit, patients completed before and after treatment visual Analog scales (VAS) of their patient's relaxation, Well-being, Vitality, anxiety, stress, nausea, vomiting; patients` heart rates were monitored during treatment to calculate HRV. The study concluded that the patients who received music therapy and relaxation improved more with music $(\mathrm{p}<0.01)$. The HRV (Heart rate variability) parasympathetic parameter was significantly lower with music ${ }^{6}$.

Lee, David and Henderson (2004) A. conducted a study to identify the effect of music on pre-procedure anxiety levels of Hong Kong Chinese patients undergoing day procedures in a local community based hospital. Altogether 113 patients fulfilled the criteria and were assigned to the control or the intervention (music-listening) group. There were 28 females and 27 males in the control group and 27 females and 31 males in the music-listening group. The number of participants in our experimental and control groups were co Paired-sample $t$-tests (one-tailed) were conducted separately for the control and the music-listening groups to examine changes in the scores on the State Trait Anxiety Inventory (STAI) and vital-sign measurements at time 1 and time 2. For the control group, there were significant decreases in diastolic pressure $[t(54)=1.93, P=0.030]$, pulse rate $[t(54)$ $=4.70, p<0.01]$ and respiration rate $[t(54)=6.02, p<0.01]$. For the music-listening group, there were significant decreases in systolic pressure $[t(57)=3.83, p<0.01]$, pulse rate $[t(57)=4.64, p<0.01]$, respiration rate $[t(57)=6.65, p<$ $0.01]$ and STAI state anxiety score $[t(57)=1.78, p=0.040]$. The results indicate that the use of self-selected music is beneficial in reducing physiological and psychological parameters $^{7}$.

Linda Chlan (1998) conducted a study on Effectiveness of a music therapy intervention on relaxation and anxiety for patients receiving ventilator assistance. Design used was two-group, pretest-posttest experimental design with repeated measures. Subjects randomized to either a 30minute music condition or a rest period. Samples composed of 54 alert, non sedated patients receiving mechanical ventilation. Results found were subjects who received music therapy reported significantly less anxiety posttest (10.1) than those subjects in the control group (16.2). Heart rate and respiratory rate decreased over time for those subjects in the music group as compared with the control group subjects. Study states that a single music therapy session was found to be effective for decreasing anxiety and promoting relaxation, as indicated by decreases in heart rate and respiratory rate over the intervention period with this sample of patients receiving ventilator assistance ${ }^{8}$

\section{Volume 6 Issue 7, July 2017 www.ijsr.net}




\section{International Journal of Science and Research (IJSR) \\ ISSN (Online): 2319-7064}

Index Copernicus Value (2015): 78.96 | Impact Factor (2015): 6.391

\section{Methodology}

This research held at tertiary care hospital Karad, academic year 2016/2017, with time of research one month. Experimental research method was used in this research. Formal written permission will be obtain from the concerned authority of the hospital and chemotherapy unit. The sample consists of 60 patients and will be selected on the basis of sampling criteria of convenient purposive sampling technique. The subject will be assigned to experimental group (30) and control group (30). Sample will be selected as per inclusion criteria of the study. Procedure will be explained and consent will be taken from all samples. The pre-test of feeling of well being will be assessed in both the experimental and control groups. The intervention (i.e. Instrumental music) will then be administered to the experimental group by the investigator for 1hour and only for one time. Then the post-test of feeling of well being will be assessed after the intervention to the experimental group as well as control group.

\section{Results}

Majority of patients $11(36.66 \%)$ belongs to experimental group were within the age group of $55-69$ years. whereas, $14(46.67 \%)$ of patients from control group were within the age group of 39-54yrs 55-69 yrs.

Both genders are equally distributed to experimental group i.e. $15(50 \%)$ whereas, $17(56.66 \%)$ of patients from control group were also female.

Majority of patients 27 (90\%) belongs to experimental group were belongs to hindu religion, whereas, $26(86.66 \%)$ of patients from control group were belongs to control.

Majority of patients 15 (50\%) belongs to experimental group had secondary education whereas, $13(43.33 \%)$ of patients from control group had secondary education.

Majority of patients $19(63.34 \%)$ belongs to experimental group were had not working occupational status, whereas 18 $(60 \%)$ patients had not working occupational status in control group.

Majority of patients $17(56.67 \%)$ from experimental group having monthly income below 5000 and in control group 19 $(63.34 \%)$ having monthly income below 5000

Majority of patients $28(93.37 \%)$ belongs to experimental group were had married marital status, whereas 25 (86.67\%) patients had married marital status in control group.

Majority of patients 21 (70\%) belongs to experimental group were had residence in rural area, whereas 25 (83.33\%) patients had residence in rural area in control group.
Table 1: Comparison of pretest and post test of feeling of well being of both control and experimental group.

\begin{tabular}{|c|c|c|c|c|c|c|}
\hline & \multicolumn{2}{|c|}{$\begin{array}{c}\text { Control } \\
\text { Group }\end{array}$} & \multicolumn{2}{|c|}{$\begin{array}{c}\text { Experimental } \\
\text { Group }\end{array}$} & $\begin{array}{c}\text { Mean } \\
\text { Difference }\end{array}$ & $\begin{array}{c}\text { Unpaired } \\
\mathrm{t} \text { test }\end{array}$ \\
\cline { 2 - 5 } & Mean & SD & Mean & SD & & \\
\hline Pretest & 45.66 & 11.16 & 46.63 & 10.49 & 0.97 & $\begin{array}{c}\mathrm{t}=0.27, \\
\mathrm{p}=0.79 \\
\text { Not } \\
\text { Significant }\end{array}$ \\
\hline Posttest & 42.93 & 10.86 & 53.50 & 9.92 & 10.57 & $\begin{array}{c}\mathrm{t}=3.93, \\
\mathrm{p}=0.0002 \\
\text { Highly } \\
\text { Significant }\end{array}$ \\
\hline $\begin{array}{c}\text { Mean } \\
\text { Difference }\end{array}$ & \multicolumn{2}{|c|}{2.73} & \multicolumn{2}{|c|}{6.87} & & \\
\hline $\begin{array}{c}\text { Paired } \\
\mathrm{t} \text { test }\end{array}$ & $\begin{array}{c}\mathrm{t}=4.10, \\
\mathrm{p}=0.0003\end{array}$ & $\begin{array}{c}\mathrm{t}=9.64, \\
\mathrm{p}=0.0001 \\
\text { Very } \\
\text { Highly } \\
\text { Significant }\end{array}$ & & & \\
\hline
\end{tabular}

Our study findings show that the unpaired t test was used to test the not significant difference between pre test of control group and experimental group. The mean difference was $(d f=0.97)(t=0.27, p=0.79)$. Similarly the unpaired t test was used to test the significant difference between post test of control group and experimental group. The mean difference was $(\mathrm{df}=10.57)$ and $(\mathrm{t}=3.93, \mathrm{p}=0.0002)$.

Paired t test was used to test the significant difference between pre test and post test of control group $(\mathrm{df}=2.73)$ $(t=4.10, p=0.0003)$. The mean of pre test of control group (45.66) which was higher than mean of post test of control group (42.93). That was indicated that the feeling of well being in post test of control group was decreased.

Paired t test was used to test the significant difference between pre test and post test of experimental group $(\mathrm{df}=6.87) \mathrm{t}=9.64, \mathrm{p}=0.0001)$. The mean of post test of experimental group (53.50) which was higher than mean of pre test of experimental group (46.63). That was indicated that the feeling of well being in post test of experimental group was increased.

This means that the instrumental music was effective on feeling of well being among cancer patients.

\section{Conclusion}

The findings of the study showed that majority of the patients from control group having decreased feeling of well being after chemotherapy with receiving routine care. After intervention there is improvement in feeling of well being of patients in experimental group. So this indicates instrumental music is effective to improve feeling of well being.

\section{Future Scope}

Keeping in view the findings of the present study, the following future scope were made:

1) A similar study can be conducted with a view to develop and implement new techniques to prevent psychological complications. 


\section{International Journal of Science and Research (IJSR) \\ ISSN (Online): 2319-7064}

Index Copernicus Value (2015): 78.96 | Impact Factor (2015): 6.391

2) A similar study can be replicated on other oncology patients receiving other treatment modality like radiation etc.

3) An exploratory survey can be done to find out the limitations faced by the patients in following feeling of well being.

\section{References}

[1] Carol, L. Kornmehi, Clinical effects of music therapy. Journal of Canadian music therapy association. March (2003) ; 9(3), 32-35.

[2] Ferrier, A. J. (2007). Effect of music therapy on stress patients. Journal of music therapy. 12(4), 32-35.

[3] Vasanthakalyani C. A study to evaluate the effectiveness of music therapy on pain and anxiety among cancer patients at Apollo hospital, Chennai. Health Action. 2007; 17-19.

[4] Sendelbach, Sue E, Halm, Margo A, Doran, Karen A, et al. Effects of music therapy on physiological and psychological outcomes for patients undergoing cardiac surgery. The Journal of Cardiovascular Nursing. 2006; 21:194-200. Available from: http://www.ncbi.nlm.nih.gov

[5] Buffum MD. A Music intervention to reduce anxiety before vascular angiography procedures. Journal of Vascular Nursing. 2006; 24 (3): 68-73. Available from: http://www.ncbi.nlm.nih.gov

[6] Buffum MD. A Music intervention to reduce anxiety before vascular angiography procedures. Journal of Vascular Nursing. 2006; 24 (3): 68-73. Available from: http://www.ncbi.nlm.nih.gov

[7] Lee, David, Handerson A. The effect of music on preprocedural anxiety Hong Kong Chinese day patients. Journal of Clinical Nursing. 2004; 13(3): 297-303. Available from: http://www.ncbi.nlm.nih.gov

[8] Chlan L. Effectiveness of a music therapy intervention on relaxation and anxiety for patients receiving ventilator assistance. Heart \& Lung. The Journal of Acute and Critical Care. 1998; 27(3): 169-176. 